\title{
Article \\ Cellular Chaperone Function of Intrinsically Disordered Dehydrin ERD14
}

\author{
Nikoletta Murvai ${ }^{1,2}$, Lajos Kalmar ${ }^{1,3}$, Beata Szabo ${ }^{1}$, Eva Schad ${ }^{1}$, András Micsonai ${ }^{4}$, József Kardos ${ }^{4}$ (D), \\ László Buday ${ }^{1}$, Kyou-Hoon Han ${ }^{5,6}$, Peter Tompa ${ }^{1,7,8}$ (D) and Agnes Tantos ${ }^{1, *}$
}

1 Research Centre for Natural Sciences, Institute of Enzymology, 1117 Budapest, Hungary; murvai.nikoletta@ttk.hu (N.M.); 1k397@cam.ac.uk (L.K.); szabo.beata@ttk.hu (B.S.); schad.eva@ttk.hu (E.S.); buday.laszlo@ttk.hu (L.B.); Peter.Tompa@vub.be (P.T.)

2 Department of Biochemistry, Institute of Biology, ELTE Eötvös Loránd University, 1117 Budapest, Hungary

3 Department of Veterinary Medicine, University of Cambridge, Cambridge CB3 OES, UK

4 ELTE NAP Neuroimmunology Research Group, Department of Biochemistry, Institute of Biology, Eötvös Loránd University, 1117 Budapest, Hungary; micsonai@ttk.elte.hu (A.M.); kardos@elte.hu (J.K.)

5 Biomedical Translational Research Center, Division of Convergent Biomedical Research, Korea Research Institute of Bioscience and Biotechnology, Daejeon 34141, Korea; yoonje55@naver.com

6 Gene Editing Research Center, Division of Convergent Biomedical Research, Korea Research Institute of Bioscience and Biotechnology, Daejeon 34141, Korea

7 VIB-VUB Center for Structural Biology (CSB), Vlaams Instituut voor Biotechnologie (VIB), 1050 Brussels, Belgium

8 Structural Biology Brussels (SBB), Vrije Universiteit Brussel (VUB), 1050 Brussels, Belgium

* Correspondence: tantos.agnes@ttk.hu; Tel.: +36-1-382-6705

Citation: Murvai, N.; Kalmar, L.; Szabo, B.; Schad, E.; Micsonai, A.; Kardos, J.; Buday, L.; Han, K.-H.; Tompa, P.; Tantos, A. Cellular Chaperone Function of Intrinsically Disordered Dehydrin ERD14. Int. J. Mol. Sci. 2021, 22, 6190. https:// doi.org/10.3390/ijms22126190

Academic Editors: Karen Skriver and Birthe Kragelund

Received: 25 April 2021

Accepted: 4 June 2021

Published: 8 June 2021

Publisher's Note: MDPI stays neutral with regard to jurisdictional claims in published maps and institutional affiliations.

Copyright: (c) 2021 by the authors. Licensee MDPI, Basel, Switzerland. This article is an open access article distributed under the terms and conditions of the Creative Commons Attribution (CC BY) license (https:// creativecommons.org/licenses/by/ $4.0 /)$.
Abstract: Disordered plant chaperones play key roles in helping plants survive in harsh conditions, and they are indispensable for seeds to remain viable. Aside from well-known and thoroughly characterized globular chaperone proteins, there are a number of intrinsically disordered proteins (IDPs) that can also serve as highly effective protecting agents in the cells. One of the largest groups of disordered chaperones is the group of dehydrins, proteins that are expressed at high levels under different abiotic stress conditions, such as drought, high temperature, or osmotic stress. Dehydrins are characterized by the presence of different conserved sequence motifs that also serve as the basis for their categorization. Despite their accepted importance, the exact role and relevance of the conserved regions have not yet been formally addressed. Here, we explored the involvement of each conserved segment in the protective function of the intrinsically disordered stress protein (IDSP) $A$. thaliana's Early Response to Dehydration (ERD14). We show that segments that are directly involved in partner binding, and others that are not, are equally necessary for proper function and that cellular protection emerges from the balanced interplay of different regions of ERD14.

Keywords: intrinsic structural disorder; plant chaperone; heat stress; structure-function relationship; dehydrin; early response to dehydration; LEA protein; CD spectroscopy

\section{Introduction}

Chaperone proteins have developed in evolution for the protection of cells against a variety of abiotic stresses, including drought, high or low temperature, osmotic stress, different salts, or heavy metals. These protective proteins come in a variety of shapes and forms as they need to be able to function under unfavorable conditions and on a plethora of different clients. One of the largest groups of chaperones are heat shock proteins (HSPs), originally identified as being expressed under conditions of elevated temperatures. These are complex globular proteins that come in a variety of sizes and utilize intricate molecular structures and interaction networks to fulfil their functions [1]. Nevertheless, not only globular proteins can serve as chaperones, as a growing body of information underlines the importance and efficiency of a chaperone class encompassing disordered proteins $[2,3]$. 
Dehydrins, which are categorized as Group 2 LEA (Late Embryogenesis Abundant) proteins, are such disordered chaperones that function in an ATP-independent manner [2]. Proteins in this family have multifunctional roles in stress response in many taxa [4]. They are generally characterized by high net charge and the presence of polar amino acids; they are enriched in glycine and lysine residues but are depleted in cysteine and tryptophan [5], suggesting a disordered character. Their categorization is based on the highly conserved segments that can be found in their sequences [6] in different combinations: (i) The Ksegment is an approximately 15 amino acid long conserved lysine-rich motif present in all cold-expressed dehydrins. It can be found in multiple copies (1-12) within a dehydrin and, according to in silico predictions, it tends to adopt an amphipathic $\alpha$-helix structure $[7,8]$. Presumably, K-segments can play a role in shaping the interaction with partner molecules, which is supported by our earlier observations [9]. (ii) The S-segment is a serine-rich region that can be phosphorylated, and, in most examples, it is wedged between the K-segments. The exact function of its phosphorylation is not yet known, but it may play a role in the protein's delivery to the nucleus or in membrane stabilization. (iii) The Y-segment is a conserved region at the $\mathrm{N}$-terminus of dehydrins that shows homology to the nucleotide binding regions of plant proteins and bacterial chaperone proteins. (iv) The ChP-segment is a highly charged, lysine-rich region that bears a strong resemblance to the charged linker region of the Hsp-90 chaperone protein found in animals. (v) The q-segment is a less conserved, apolar region composed of glycine or proline and alanine amino acids, usually located between two K-segments $[6,10]$.

The Arabidopsis thaliana genome encodes for 10 different dehydrins that probably have partially overlapping functions [11,12]. ERD14 is one of the A. thaliana dehydrins that belongs to the SK2 dehydrins subgroup, and it contains an additional hydrophobic region ( $\mathrm{H}$ region) in its sequence. Its expression is induced under different stress conditions, such as heat and osmotic stress, and it can also be found in high quantities in rapidly dividing tissues, such as meristems [13]. In vitro and in vivo studies have indicated that ERD14 is a potent chaperone for a number of substrates [14,15]. Experiments with lysozyme, alcohol dehydrogenase, luciferase, and citrate synthase model substrates have shown that this protein is capable of preventing heat-induced loss of activity and subsequent aggregation of the enzymes [3]. They did not show, however, a chaperone activity in reactivating denatured proteins, and the exact mechanism of its chaperone function is yet unknown.

Conserved segments in ERD14 create a specific pattern of charge- and structuredistribution that may be crucial for the proper chaperone function of the protein.

The balanced distribution of charged amino acids throughout the full length of the protein results in a sequence that has a low overall negative charge $(-9$ at neutral $\mathrm{pH}$ resulting from 46 negatively and 37 positively charged sidechains) carrying a significant portion of charged regions (Figure 1). The $\mathrm{N}$-terminal half of the protein is negatively charged, with two non-conserved, disordered regions of strong negative charge, while the C-terminal region partly compensates for this, mainly through the region of the Chpsegment consisting of 15 charged residues out of 18 (in green on Figure 1). K-segments (blue on Figure 1) achieve neutral net charges by alternating positively and negatively charged residues, a pattern that might be important in partner binding [9]. The S-segment (yellow on Figure 1), on the other hand, consists mostly of polar, non-charged amino acids, whose exact relevance is not yet clear, although phosphorylation of the serine sidechains may have a regulatory function. The H-segment (red on Figure 1) also lacks charged residues, but it is highly hydrophobic and contains several proline residues. This may be important for the recognition of exposed hydrophobic patches on partner proteins while also helping to keep ERD14 in a disordered structural state.

In our previous work, we identified several different E. coli proteins bound by ERD14, supporting the idea of its promiscuous protein binding and protection. We provided evidence that ERD14 is localized in the cytoplasm during heat stress, arguing against its functioning through membrane protection [9]. Our in-cell NMR measurements also confirmed that the conserved K-segments that sample helical structural states in vitro [16] are 
the ones that participate mainly in molecular interactions, while most of the other regions remain disordered. Nevertheless, being able to bind proteins is not the only prerequisite of chaperones, highlighting the importance of the regions outside of K-segments in the function of ERD14.

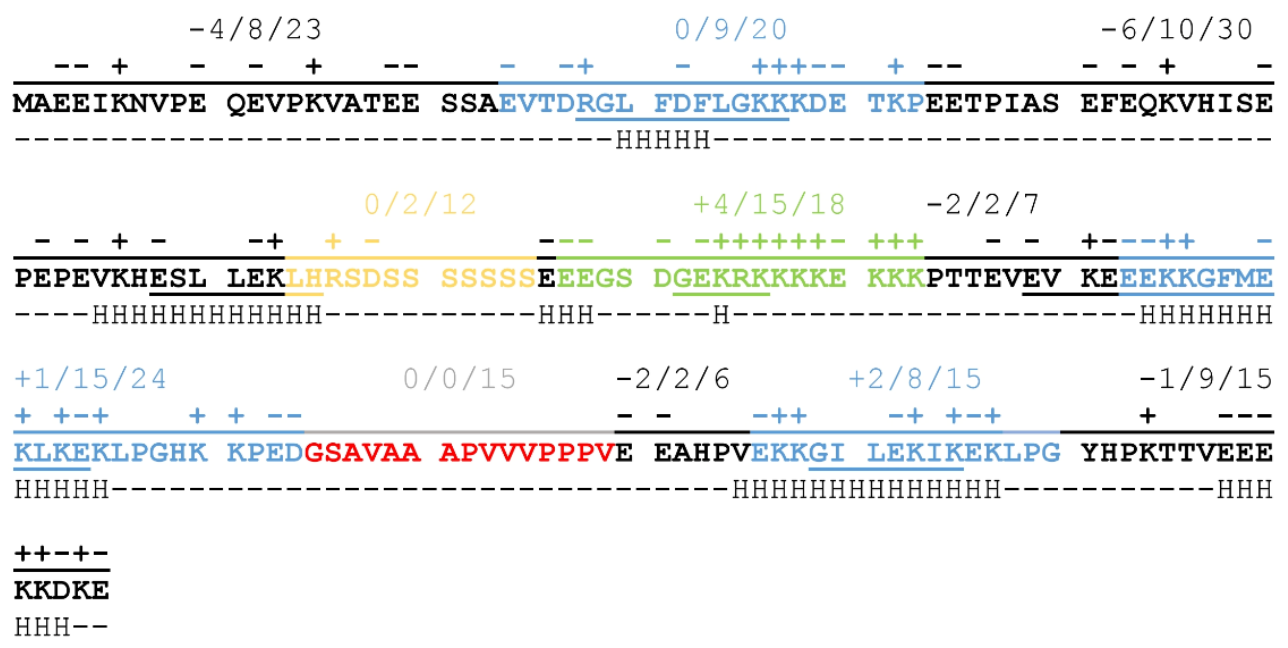

Figure 1. Conserved segments, charge distribution, in silico, and experimental $\alpha$-helical propensities of the ERD14 protein. Conserved regions: Ka-, Kb-, Kc- (blue), S- (yellow), Chp- (green), and Hsegment (red) indicated in the sequence of ERD14. In addition to individual charges above the regions, net charge/number of charged side chains/length of regions summed up. Underlined letters show residues with $\alpha$-helical propensity calculated from nuclear magnetic resonance (NMR) chemical shifts $[9,16]$ by $\delta 2 \mathrm{D}$ method [17]. Below the residues, $\mathrm{H}$ indicates the $\alpha$-helical propensity estimated by in silico PredictProtein analysis [18-20].

In order to gain deeper insight into the molecular architecture needed for the protective function of ERD14, we designed several mutants by deleting one or more of the conserved regions (1x: $\Delta \mathrm{Ka}, \Delta \mathrm{Kb}, \Delta \mathrm{Kc}, \Delta \mathrm{Chp}, \Delta \mathrm{H}, \Delta \mathrm{S} ; 2 \mathrm{x}: \Delta \mathrm{Kab}, \Delta \mathrm{Kbc}, \Delta \mathrm{Kac} ; 3 \mathrm{x}: \Delta \mathrm{Kabc})$ or prepared scrambled mutant sequences (Full-Scr, Scr-KabcS, Scr-Kabc, ScrKcS, Scr-Kc, Scr-S) and determined the heat-resistance of E. coli cells, expressing the different mutants and studying the structural consequences of the deletions or sequence modifications.

\section{Results}

ERD14 is a typical representative of the SK2 group that harbors several potentially important sequential features. In addition to its unique charge-distribution, secondary structural elements are also dispersed along the sequence of ERD14. As indicated on Figure 1, short helical regions can be found mostly in the K-segments, but a non-conserved region at the border of the S-segment, as well as the ChP-segment, samples helical conformations in vitro, as suggested by NMR spectroscopy [16]. The observed patterning of charges and secondary structural elements suggest that the different regions have specific functions and possibly cooperate with each other to achieve biological function.

To assess the contribution of different regions of ERD14 to the protective effect of the protein, we developed a system using a heat-treatment that reduces the viability of E. coli cells to around $25 \%$ of the original value (Figures 2 and 3B). After testing various conditions (Figure 2), we chose a treatment of $50{ }^{\circ} \mathrm{C}$ for $15 \mathrm{~min}$, as this gave the optimal difference between the stressed and non-stressed cells, allowing a wide dynamic range to detect differences in survival rates. The protective effect of each ERD14 variant was assessed as the difference of the survival rate (DSR) of the cells compared to the ones expressing the wild-type protein. This system has already proved to be useful for the determination of the in vivo structural state and the molecular partners of ERD14 [9], and it has several beneficial aspects for our purposes. Most importantly, it enabled us to investigate several different protein constructs in a timely manner and, by eliminating the redundancy of plant chaperones [12], it largely 
simplified the interpretation of the results. Because dehydrins are known to have broad substrate specificity [21-23], and we were able to identify several partner proteins of ERD14 in E. coli cells, we found this system to be an appropriate model system for our study.

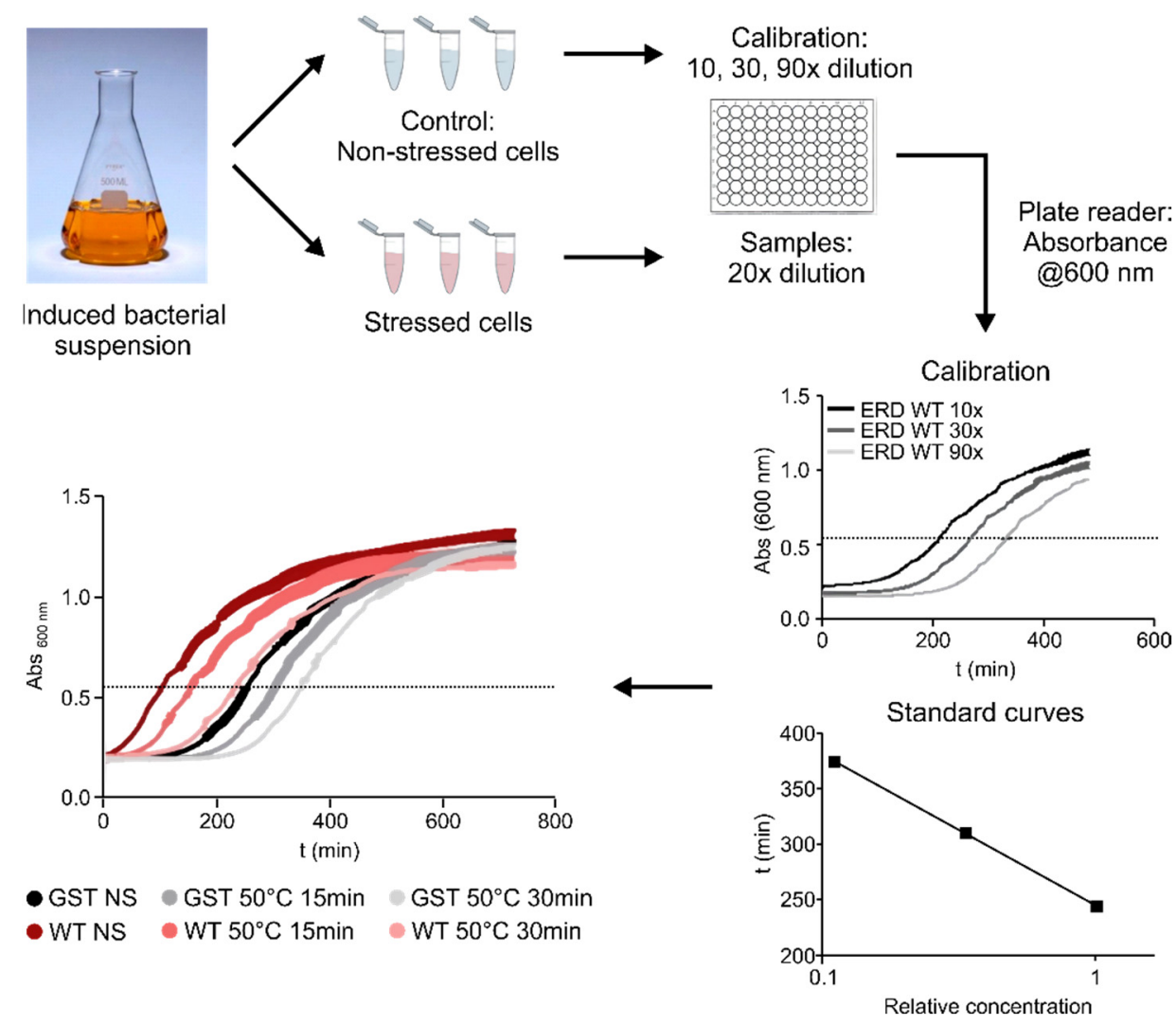

Figure 2. Overview of the viability assay. After a standard induction period, cells were stressed by a heat shock of $50{ }^{\circ} \mathrm{C}$ for $15 \mathrm{~min}$ (final set-up, after optimization of the stress conditions by screening at different temperatures for different time length shown at the left bottom panel). Viability of stressed and non-stressed samples were compared based on their cell growth after appropriate dilution in fresh medium (Calibration-grey curves). Cell growth was followed by absorbance at $600 \mathrm{~nm}$. Half-time of growth curves varies linearly, with dilution plotted on a logarithmic scale, i.e., it is informative of the concentration of viable cells in the sample. For our experiments, we have set the OD at 0.6 as this period of growth by convention and applied serial dilutions to obtain the calibration curve and calculate the relative survival ratios of the different samples (NS: non-stressed samples, S: stressed samples). Based on this, we can compare the viability of cells exposed to the same stress conditions but expressing various constructs (colored curves).

Our initial results confirmed that wild type ERD14 is capable of protecting cells against the applied heat stress, increasing their survival rate to $70 \%$ (Figure 3B). None of the control proteins were capable of such protection, and induction of an empty expression vector did not affect stress resistance either. The importance of specific sequential components (Figure $3 \mathrm{~A}$ ) in the function of the protein was suggested by the fact that a variant with similar amino acid composition but randomized sequence (Full-Scr) did not protect the $E$. coli cells against heat stress (Figure 3B).

Our structural studies indicated that the conserved K-segments were primarily involved in direct partner binding within the cells [9], prompting us to design a series of deletion mutants targeting these regions (for constructs, cf. Supplementary Table S1). Even though the other conserved ERD14 regions, the S-, Chp-, and H-segments, did not appear to play major roles in partner recognition, we have also created deletions of these as well to determine if they contributed to the chaperone effect. The constructs were expressed in $E$. 
coli (at levels comparable to that of WT ERD14, cf. Supplementary Figure S1), and their protective effects in the cell viability assay were measured (Figure 2).

A

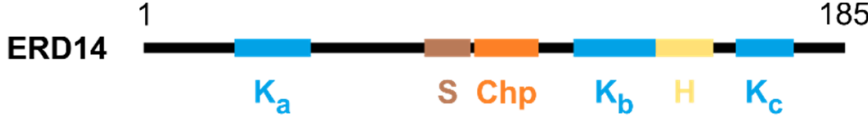

$\mathrm{B}$

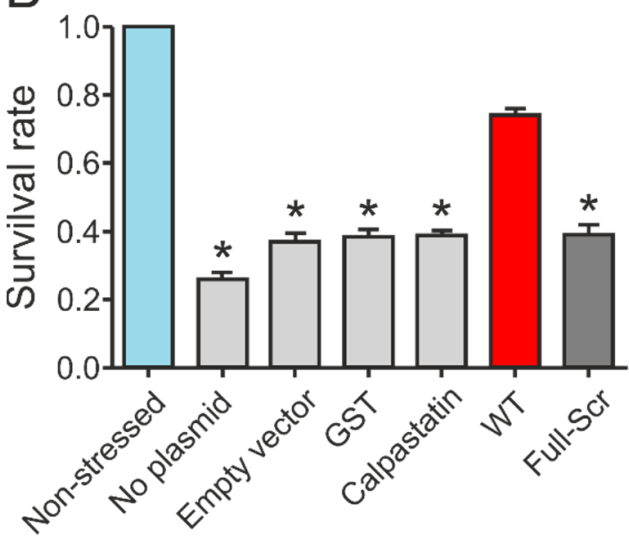

C

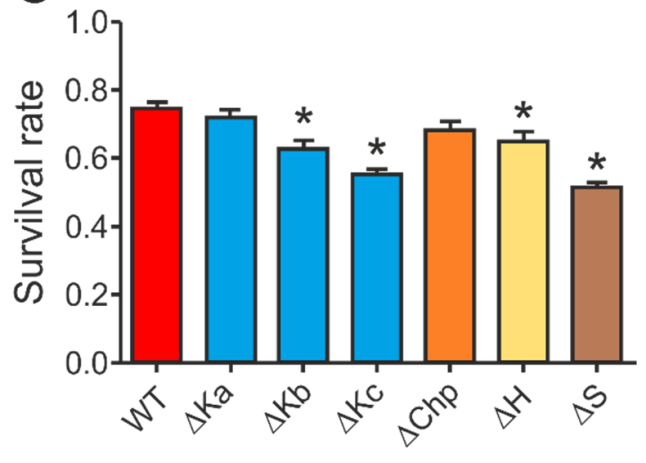

Figure 3. Conserved regions of ERD14 contribute to cell protection. (A) Schematic representation of the conserved regions within ERD14. (B) Survival rate (viability) is reduced by the applied heat stress to $26.2 \%$ (compared to non-stressed cells) for non-transformed cells, $36.8 \%$ for cells containing an empty vector, and about 39\% in the case of overexpression of control proteins: GST (38.4\%) and IDP calpastatin (38.7\%). Overexpression of ERD14 increases the survival rate to $74.5 \%$. Removing the conserved regions by randomizing the amino acid sequence (Full-Scr) abolished the protective effect (viability 38.9\%). (C) Protective effect of a series of mutants in which conserved regions of the protein have been individually deleted. Data represent mean \pm SEM and the results of at least 18 parallels for each construct. Significant differences $(p<0.05)$ compared to WT ERD14 are labeled with asterisks $\left(^{*}\right)$.

Deletion of different conserved regions affected the chaperone activity of ERD14 to different extents (Figure $3 \mathrm{C})$. Of the three K-segments, removal of $\mathrm{Kc}_{\mathrm{c}}(\Delta \mathrm{Kc})$ impaired activity the most, reducing the remaining cell viability from $74.5 \%$ (wild type) to $54.9 \%$ (DSR: 19.6\%). The observed level of protection was always normalized to the actual expression level of the given construct, assuming linearity of response (cf. Experimental Procedures and Supplementary Figure S2). Survival rates changed linearly with increasing ERD14 concentrations for the wild type and the $\Delta$ Kc mutant ERD14 when we applied an IPTG-inducible system, as well as in an arabinose-inducible set-up. The latter enabled us to avoid the side effects of changing cellular density during elongated expression times. The reduction in protection by deleting the S-segment was the most pronounced (DSR $23.4 \%$ ), and it is commensurable with that of Kc. The deletion of Kb (DSR 11.9\%), H (DSR $9.8 \%$ ), and Chp (DSR 6.6\%) have intermediate effects, whereas deletion of Ka (DSR 3\%) causes almost no change in activity. These results suggest that Kc and $\mathrm{S}$ are the primary sites of activity, together with varying contributions of other segments. These notions were further confirmed by the in vitro chaperone activities of these mutants (Supplementary Figure S3 and Table S4). In these experiments, the $\Delta \mathrm{Kc}$ and $\Delta \mathrm{S}$ variants showed similarly reduced chaperone activities as the FS ERD14 variant. This is an interesting observation, especially in light of the fact that all K-segments participate in partner binding within a cell, whereas the S-segment does not [9]. Although partner binding in itself is a property of large amounts of proteins, only a small portion of them exhibit chaperone activity. Beyond the necessary partner binding regions, a chaperone is expected to have segments that contribute to or are responsible for chaperone function, such as the S-segment. 
Because the ChP-segment and the three K-segments tend to adopt $\alpha$-helical conformations, as detected by NMR $[9,16]$, we compared the helix content of the different single deletion mutants by CD spectroscopy. In phosphate buffer, all tested proteins showed a CD spectral shape characteristic of a disordered protein (Figure $4 \mathrm{~A}$ ), very similar to that of the wild-type ERD14. Because CD spectroscopy reflects the average secondary structure content, this indicates that the free ERD14 molecules are essentially disordered, and the helices shown by NMR [9] are truly only transient and might be stabilized by interacting with partner molecules. The inherent tendency of the wild-type protein and the deletion mutants to form $\alpha$-helical structures was confirmed by testing their structure in the presence of the helix-inducing trifluoro-ethanol (TFE). The addition of $30 \%$ TFE increased the helicity of the wild-type protein from 5\% to 25\% (Figure 4B). Deletion of the $\mathrm{K}$ segments reduced the helicity in TFE to $16-21 \%(21 \%, 20 \%$, and $16 \%$ for $\Delta \mathrm{Ka}, \mathrm{b}$, and c, respectively), indicating that the overall structure of the protein was probably not perturbed in these mutants. Similar observations were made for the S-segment, which had a residual helicity of $20 \%$ in TFE. Removal of the $\mathrm{H}$-segment resulted in a minor change in helix-forming tendency ( $23 \%$ helix content in TFE), and the $\Delta$ Chp variant also showed a somewhat reduced helix-forming tendency with $22 \%$ helix content. In contrast to the single deletion mutants, the Full-Scr ERD14 variant remained almost completely disordered, with only 9\% helix content even in the presence of TFE (Figure 4C,D). Intriguingly, the loss of helicity by deletion of the individual segments sums up significantly more than the overall helix content of WT ERD14 (67 residues vs. 46, respectively), which indicates that the structure-forming tendencies of the segments are not independent, nor additive, and there might be an interplay between ERD segments.

Table 1 shows the changes in the number of residues that are in $\alpha$-helical conformation in the presence of TFE in the single deletion mutants, compared to the wild-type protein, thus we can gain valuable insight into the helix-forming tendencies of each conserved segment.

Table 1. Effects of the deletions on the helical propensity of ERD14.

\begin{tabular}{cccccccc}
\hline & $\mathbf{\Delta K a}$ & $\mathbf{\Delta K b}$ & $\boldsymbol{\Delta} \mathbf{K c}$ & $\boldsymbol{\Delta C h p}$ & $\boldsymbol{\Delta H}$ & $\boldsymbol{\Delta S}$ & Full-Scr \\
\hline \# of residues deleted & 20 & 22 & 15 & 17 & 15 & 12 & 0 \\
$\begin{array}{c}\text { Change in the \# of } \\
\text { res. in helix }\end{array}$ & -10 & -12 & -18 & -9 & -7 & -11 & -29 \\
$\quad$ DSR & $3.0 \%$ & $11.9 \%$ & $19.6 \%$ & $6.6 \%$ & $9.8 \%$ & $23.4 \%$ & $35.6 \%$ \\
\hline
\end{tabular}

Intriguingly, the PredictProtein online bioinformatics structure analysis tool ([20]) predicts $\alpha$-helix for 50 residues in the ERD14 sequence, which is far more than experimentally observed by $\mathrm{CD}$ under native conditions ( 9 residues); however, the prediction fits well to the CD analysis of the TFE-induced structure (46 residues in $\alpha$-helix). NMR measurements are also in good correlation with this, as 44 residues show transient helical conformations in vitro [16]. These are not stable enough for the $\mathrm{CD}$ to pick up in phosphate buffer, but as we can see, they can be stabilized and measured by the addition of TFE. PredictProtein assigns all three K-segments as helical; however, similarly to CD (Table 1), it predicts the lowest helicity for Ka. It also indicates some helicity for Chp and $\mathrm{S}$ and for regions that are located outside of the conserved segments. Apart from three residues located sporadically in $\beta$-sheet, the rest of ERD14 is predicted to be disordered. These bioinformatics results are partly fit to the experimental ones of CD and the earlier NMR, and while being useful, should be handled with caution.

If we compare the structural effects observed by $\mathrm{CD}$ spectroscopy with the changes in the survival rates of bacteria expressing different constructs (Table 1 and Table S3), we can draw interesting conclusions regarding the structure-function relations of ERD14. While the structural changes induced by removing each of the K-segments were substantial, Kc causing the highest, their effect on the activity of the protein differed more significantly. While the deletion of Kc caused the highest activity decrease, Ka, despite its helix contribution, had almost no effect on activity. Conversely, the $\Delta \mathrm{H}$ mutant was a significantly less 
effective chaperone than the WT protein, even though the change in $\alpha$-helical content was the lowest (Figure 3B and Table 1). The deletion of the ChP-segment resulted in a moderate reduction of helicity, while it did not significantly affect the protective activity. Finally, removing all structural tendencies and sequence motifs by randomizing the full sequence of the protein results in a complete loss of activity (Figure $3 \mathrm{~A}$ and Table 1).
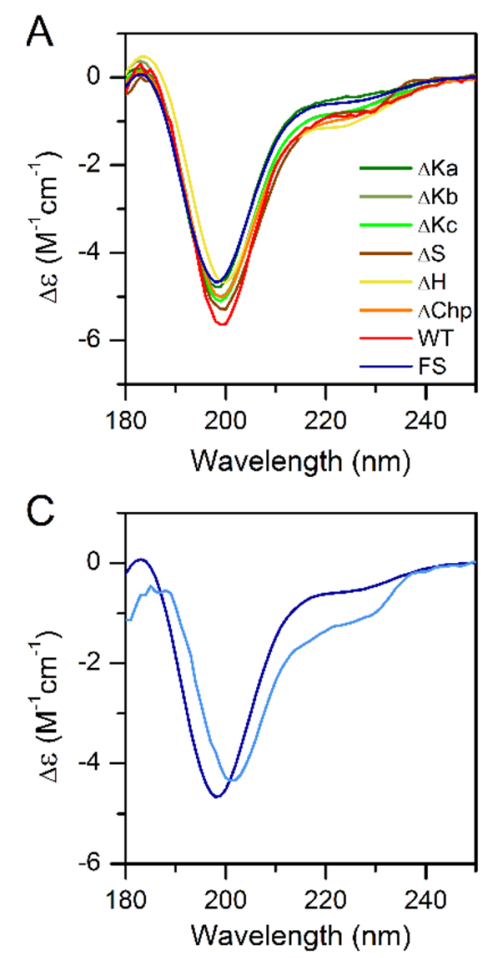

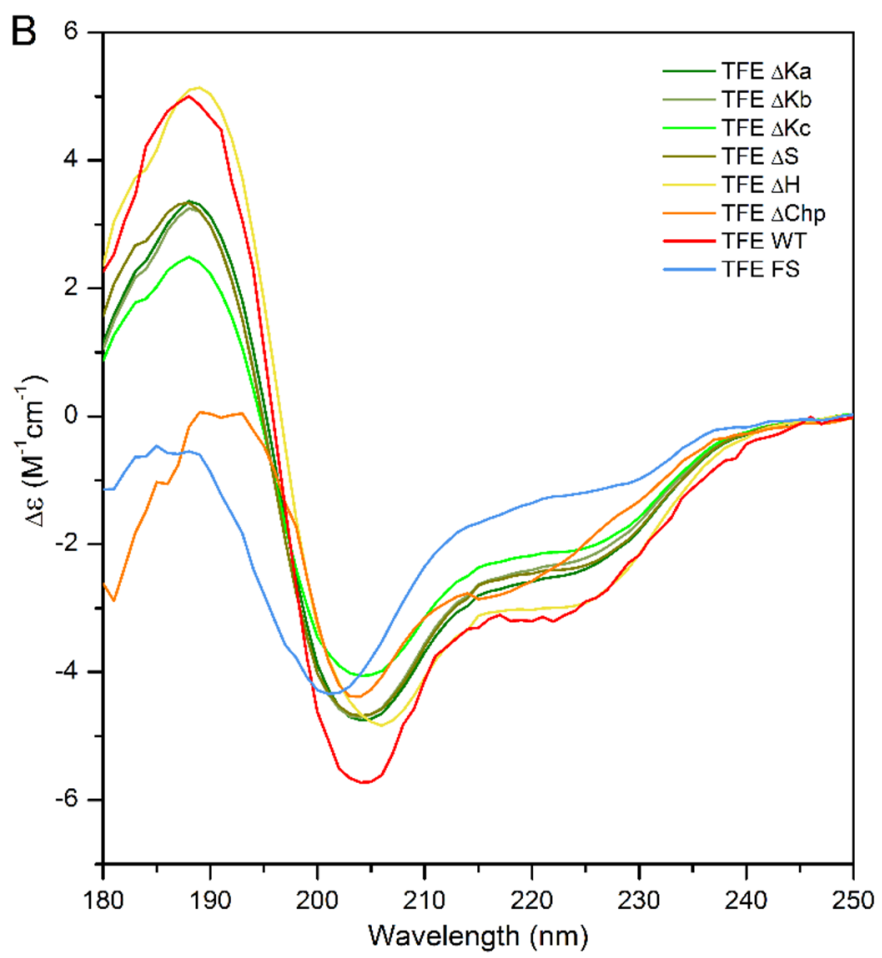

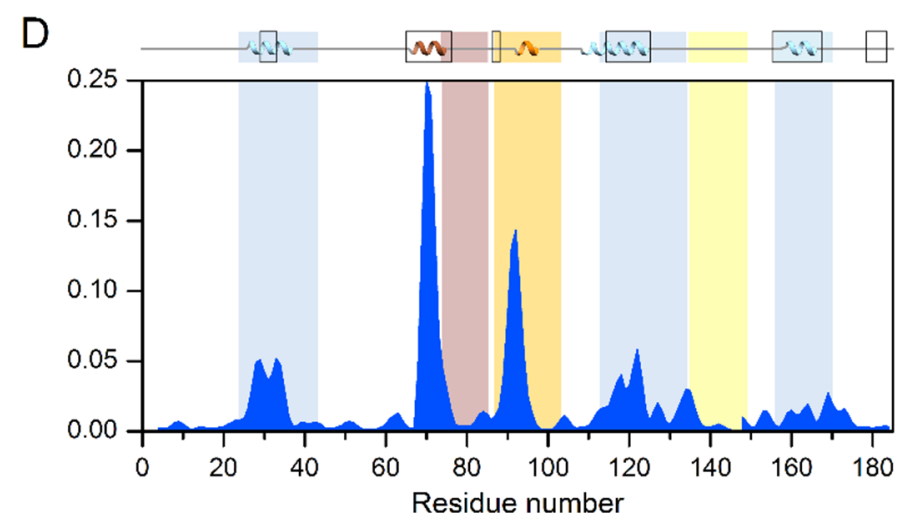

Figure 4. CD measurements of single deletion mutants and Full-Scr construct of ERD14 with TFE induced secondary structure changes. (A) Circular dichroism spectra of the $\Delta \mathrm{Ka}^{-}, \Delta \mathrm{Kb}-, \Delta \mathrm{Kc}_{-}, \Delta \mathrm{S}_{-}, \Delta \mathrm{H}_{-}, \Delta \mathrm{Chp}-$, and Full-Scr (FS) constructs of ERD14, recorded in $10 \mathrm{mM}$ Na-phosphate buffer ( $\mathrm{pH}$ 7.4), indicating similar, mainly disordered, structures, which is demonstrated by a characteristic minimum below $200 \mathrm{~nm}$ and low amplitude around $220 \mathrm{~nm}$. (B) CD spectra of the different constructs of ERD14 recorded in Na-phosphate buffer containing 30\% TFE. There are significant differences in the extent of the induced secondary structure, as shown by the spectral differences between the variants. (C) Comparison of the CD spectra of the FS ERD14 variant in native (dark blue) and in 30\% TFE containing (light blue) buffer, indicating minor effects of TFE on the structure of the variant with scrambled sequence. (D) The degrees of formation of $\alpha$-helices (blue areas) obtained with the $\delta 2 \mathrm{D}$ method [17] using Nuclear Magnetic Resonance Chemical shifts mapped to the WT ERD14 sequence, and its graphical representation inserted above the diagram shows good accordance with the in-silico estimated $\alpha$-helix content [20] (boxes at the top). 
Taken together, these observations suggest that secondary structure formation is a necessary, but not sufficient, prerequisite of the protective effect of ERD14, as partner binding and a detectable redundancy of the regions also play important roles.

Based on the results of the survival assays and the CD measurements, we concluded that there is a significant redundancy of the motifs that manifests at several levels in the apparent exchangeability of individual motifs. This is shown by deleting multiple motifs (Figure 5A). For example, the chaperone activity of the deletion mutant $\Delta \mathrm{Kc}$ is not further reduced by the deletion of the Ka or Kb segment (cf. $\triangle$ Kac: DSR $15.7 \%, \Delta K b c$ : DSR $14.7 \%$, and $\Delta \mathrm{Kabc}$ : DSR $15.6 \%$ ), i.e., the $\mathrm{Ka}$ and $\mathrm{Kb}$ segments are rather redundant and, without the more effective Kc or S-segment, are of little additional effect. Furthermore, $\triangle \mathrm{Kab}$ (DSR $4.2 \%$ ) is almost as effective a chaperone as WT ERD14, i.e., even $\mathrm{Ka}$ and $\mathrm{Kb}$ combined have little protective function. Surprisingly, the single deletion of $\mathrm{Kb}$ caused more significant reduction (DSR 11.9\%), suggesting that there might be a complex interplay between the segments. Combined deletion of the Kc and S-segments renders the protein almost completely ineffective ( $\Delta$ KcS: DSR $34.1 \%$ vs. Full-Scr: DSR $35.6 \%$ ), while deletion of the H-segment together with the Kc increases the activity loss of either of the segments deleted alone ( $\Delta \mathrm{KcH}$ : DSR $26.8 \%$ vs. $\Delta \mathrm{Kc}$ : DSR $19.5 \%$ and $\Delta \mathrm{H}$ : DSR $9.8 \%$ ).
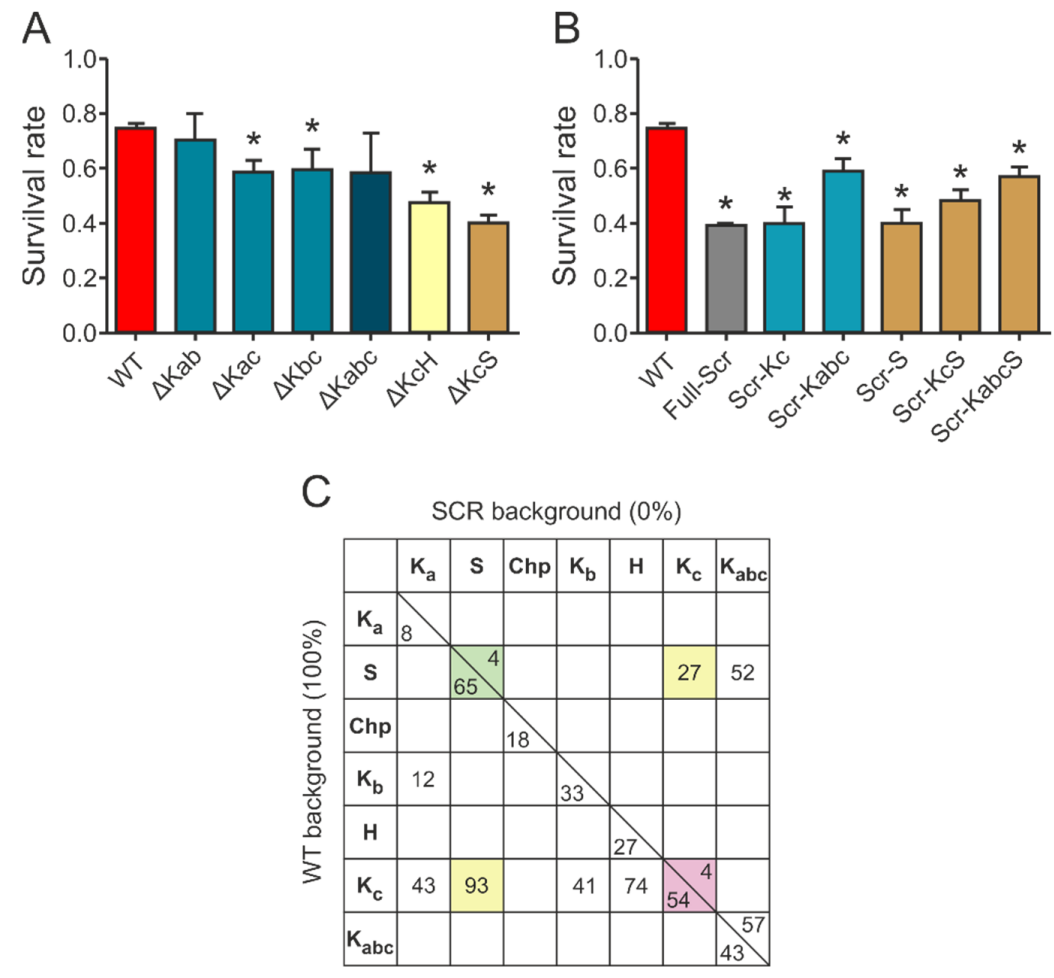

Figure 5. Interplay of different conserved elements in ERD14. (A) Protective effect of double- and triple deletion mutants, in which two or three segments are deleted (K-segments $\mathrm{Ka}, \mathrm{Kb}$, and $\mathrm{Kc}$, as well as Chp-, S-, and H-segments; cf. sequence: Supplementary Table S1). Data represent mean \pm SEM and the results of at least 18 parallels for each construct. Significant differences $(p<0.05)$ compared to WT ERD14 are labeled with asterisks $\left(^{*}\right)$. (B) Protective effect of scrambled mutants, in which either the full sequence is scrambled (Full-Scr), or particular binding regions are kept intact (e.g., $\mathrm{Kc}$ in Scr-Kc) and the rest of the sequence is randomized. Data represent mean $\pm \mathrm{SEM}$ and the results of at least 18 parallels for each construct. Significant differences $(p<0.05)$ compared to WT ERD14 are labeled with asterisks $\left({ }^{*}\right)$. (C) The relative \% contributions of motifs of ERD14 (Ka, S, Chp, $\mathrm{Kb}, \mathrm{H}$, and $\mathrm{Kc}$ ) and their combinations (e.g., $\mathrm{KcS}$ is combined $\mathrm{Kc}$ and $\mathrm{S}$ ) are quantified, as given in Materials and Methods (Supplementary Table S2). Their \% contributions to the activity above the given background, WT ERD14 and Full-Scr ERD14, either alone or in combinations, are presented in a matrix. Numbers highlighted in color demonstrate that effects are usually higher in the WT than in the scrambled background. 
In an attempt to gain a deeper insight into the functional interplay of the different conserved segments, we created a further variety of mutants in which different elements of ERD14 were modified, either individually or in various combinations (cf. Supplementary Table S1). First, we have investigated if any of the effective motifs, combined with the rest of the proteins, scrambled (kept disordered but without any recognizable sequence motifs), has a protective effect (Figure 5B). Keeping any of the most effective segments (Scr-Kc or Scr-S) results in a protein with negligible chaperone activity, similar to the entirely scrambled protein (Full-Scr). Keeping two segments (Scr-KcS) results in a more active protein, whereas keeping three (Scr-Kabc) or four (Scr-KabcS) makes it an even more potent chaperone. The importance of the other sequential elements is underlined by the fact that keeping even four segments intact cannot completely rescue the chaperone activity of the protein.

These results support a mechanism where binding at multiple points is complemented by the functional role of a disordered linker and/or terminal regions of ERD14.

Our previous observations $[9,14,16]$, combined with the results detailed above, suggest that ERD14 functions by an interplay of transient partner binding via short binding motifs and space filling by significant residual disorder in the linker and flanking regions. To gain a deeper insight into the structure-function relationship of the protective effect of ERD14, we devised a strategy to quantitate and compare the contribution of different segments of the protein to its in vivo activity. We found that scrambled ERD14 has no activity $(0 \%)$ and have taken the activity of WT ERD14 (under the given conditions) as 100\%. We then argued that, for a deletion construct in the WT background, the addition of the given motif would restore activity to $100 \%$, i.e., its contribution corresponds to the reduction of activity upon its deletion. For scrambled mutants, we argue that the addition of the given region to the inactive scrambled construct (Full-Scr) raises activity from $0 \%$ to the level measured, i.e., the contribution of the segment in the Scr background corresponds to the activity measured for the given construct. The numbers thus calculated (Supplementary Table S2 and Figure 5C) show that the two numbers for the same region (i.e., for WT and Scr background) are different, which points to a strong synergy between different, conserved, and linker regions of the protein and allows several mechanistic conclusions.

\section{Discussion}

\subsection{The Role of K Segments}

Our results point to the importance of short segments of ERD14 in its protective function, in particular the $\mathrm{K}$-segments $\mathrm{Kb}$ and $\mathrm{Kc}$, and the $\mathrm{H}$ and $\mathrm{S}$ motifs. There have been multiple prior links of evidence for the importance of K-segments in dehydrins. First of all, these and the S-segment are the most conserved regions in dehydrins. Dehydrins are actually defined and classified by the architecture of these segments [24,25], e.g., ERD14 is classified into the SK2 family, primarily because Ka has little similarity to the canonical $\mathrm{K}$-segment. In vitro studies have shown that deletion of K-segments of wheat dehydrin DHN-5 renders the protein inactive [26], whereas sequential removal of K-segments from ERD10 causes a gradual decrease in its protective activity [27]. Interestingly, in 8 out of 10 dehydrins from $A$. thaliana, $\mathrm{K}$-segments occur more than once, up to $6 \mathrm{~K}$-segments in protein $\mathrm{XERO} 2$ [24], which is a strong evolutionary argument for the operation of a chaperone model relying on multivalent binding.

Whereas the interaction of K-segments with partners via motifs follows from our results and many prior observations $[9,28]$, the exact mode of interaction with client proteins remains an open question. The detailed nature of interaction cannot be ascertained from in vivo analyses, but detailed studies of traditional chaperones suggest that hydrophobic interactions must play an important role [29]. The H-segment is hydrophobic, whereas Ksegments constitute amphipathic helices with a hydrophobic face [30]. Prior to stress, they probably use their charged face to bind to the surface of native proteins, and when protein clients start to unfold under stress, a switch to their hydrophobic face can be surmised. In 
all, induced folding is probably an important element of partner recognition by binding motifs of ERD14 [9].

\subsection{Synergy and Redundancy of ERD14 Segments}

From analyzing and comparing the relative contribution of the various segments to cellular protective function, more detailed insight can be gained. (i) The function of ERD14 is distributed in the sequence, i.e., practically all regions of the disordered chaperone contribute to its function (there is no 0 along the diagonal on Figure 5C). That is, unlike with folded proteins, enzymes, or classical chaperones, there is not one particular region whose deletion abolishes activity, while the binding of any region alone is not sufficient for cellular protection. (ii) Different regions carry different portions of function: $\mathrm{S}$ and Kc being the strongest, and Ka the weakest. (iii) Distribution also comes from the fact that more regions always contribute more to the effect; in WT background: $\mathrm{Kac}>\mathrm{Ka}, \mathrm{KaS}>\mathrm{S}$, and $\mathrm{Kc}$ and $\mathrm{Kbc}>\mathrm{Kb}$, whereas, in the Scr background, $\mathrm{KcS}>\mathrm{Kc}$ and S. (iv) The numbers also infer synergy with further regions of the protein. That is, both Kc and $\mathrm{S}$ (and the two combined, i.e., KcS) have much stronger contribution in the WT than in scrambled background, i.e., they functionally synergize with further motifs/regions. This appears to be primarily the $\mathrm{H}$-segment, as $\mathrm{Ka}$ or $\mathrm{Kb}$ do not add much to the contribution of $\mathrm{Kc}$. In fact, if we sum the contribution of all the individual motifs (numbers along the diagonal, on the WT background side), they add up to about $200 \%$, meaning they do not act independently of each other. (v) This notion of interdependent activity of the different conserved regions is further corroborated by our structural studies. The effect of deletion of K-segments caused a significant decrease in helicity. While Kc exhibited the highest effect, similarly to its highest protective effect among K-segments, the decrease in helicity is not proportional to the loss in the protective effect, especially for Ka. The removal of the otherwise hydrophobic $\mathrm{H}$ region results in the lowest change in helicity; however, it has a significant protective effect. Removal of the polar but weakly charged S-segment significantly decreases the ability of the protein to form helices, even if NMR and bioinformatics do not assign much helix for this region, indicating its possible structure-stabilizing role on the other segments of ERD14. The fact that the structural changes induced by deletion of the individual segments does not lead to a similar level of activity loss suggests that secondary structure is not the only premise of activity in the case of ERD14. (vi) As Kc (a region binding to partners) and $S$ (a region that remains disordered) [9] dominate the protective effects, this points to the functional interplay of binding and disordered regions in the cellular chaperone function of ERD14. (vii) With regards to the functionally important and conserved S-segment [24], it remains unbound and disordered in our system [9], thus it probably contributes to increasing the solvation potential of ERD14. Further, as dehydrins-among them ERD14are known to be regulated by phosphorylation [31,32], ERD14 may be most effectively regulated by phosphorylating serines in the S-segment. (viii) Taking into account the differences in the density of charged residues, net charge, hydrophobicity, and amino acid composition of the various regions of ERD14, and comparing it to the observed protective effects and secondary structure tendencies, it seems obvious that they contribute to the chaperone activity in different aspects in a synergistic manner, including the transient binding of a variety of partner molecules, keeping the solubility of the complex, stabilizing the folding of the partner, and protecting it against aggregation.

\section{Materials and Methods}

\subsection{Cell Viability Assays}

Cell viability was measured in the LB medium, by observing the time it takes for cells to reach an optical density of 0.6 at $600 \mathrm{~nm}$ of appropriately diluted samples. To this end, BL21 Star (DE3) E. coli cells, overexpressing one of various ERD14 constructs or control proteins (GST, calpastatin (CAST)), were grown in $5 \mathrm{~mL} \mathrm{LB}$ medium containing $50 \mu \mathrm{g} / \mathrm{mL}$ carbenicillin overnight at $37^{\circ} \mathrm{C}$ under continuous shaking at $200 \mathrm{rpm}$. The next day, $50 \mu \mathrm{L}$ aliquots were transferred into $5 \mathrm{~mL} \mathrm{LB}$ medium containing $50 \mu \mathrm{g} / \mathrm{mL}$ carbenicillin and 
were grown for $2 \mathrm{~h}$. Protein expression was induced with $0.5 \mathrm{mM}$ IPTG for $3 \mathrm{~h} ; 0.5 \mathrm{~mL}$ aliquots were taken and either stressed or not stressed before appropriate dilution into LB medium into the wells of a 96-well plate. Measurements of absorbance at $600 \mathrm{~nm}$ were taken every $2 \mathrm{~min}$ in a BioTek Synergy Mx microplate reader for $12 \mathrm{~h}$ at $37^{\circ} \mathrm{C}$ by $200 \mathrm{rpm}$ shaking; viability was associated with the time taken for the cells to reach an optical density of 0.6 , roughly the half-maximal value they attain after long incubation periods (cf. Figure 2). From a number of different conditions, we selected $50{ }^{\circ} \mathrm{C} \times 15$ min for an optimal stress effect-as defined by a survival rate of the untransformed cells between $20 \%$ and $30 \%$. This provides a wide dynamic range to assess the protective effects of the different overexpressed protein constructs. The observed protection effect was normalized to the actual expression level of the given construct in the given experiment, enabled by the linearity of dependence (cf. Supplementary Figure S2). In short, the actual concentration was determined, and the expected protection at a concentration matching that of WT ERD14 was calculated by linear intra- or extrapolation. Further details, such as optimization of the assay, and varying concentration of constructs, are given in Supplementary Information.

\subsection{Constructs, Recombinant Proteins, Mutagenesis}

Various deletion constructs of ERD14 were generated from the wild-type sequence by PCR. Scrambled sequences (Full-Scr, Scr-Kc, Scr-S, Scr-SKc, Scr-Kabc, and Scr-KabcS), designed in silico, were generated by total cDNA synthesis. For in-cell stability determination, ERD14 was FLAG-tagged by inserting it into the expression vector pT7-FLAG 2. Sequences of all constructs and the control proteins are delineated in Supplementary Table S1, whereas construction details can be found in Supplementary Information.

Differential survival rate (DSR) was calculated as follows: percentage of cells expressing specific mutant constructs that survived the applied heat stress was extracted from the percentage of survival when the WT ERD14 was expressed, i.e., if the survival rate was $80 \%$ for the WT and 50\% for a mutant, then the DSR of the specific mutant is $30 \%$. This means that the larger the DSR, the less efficient a chaperone the mutant is.

\subsection{Scrambled ERD Mutants}

We used a multistep approach during the design of the scrambled ERD14 mutants: (i) we generated 10,000 random sequences by using the amino acid composition of ERD14, keeping the sequence set non redundant during the process; (ii) we used IUPred [33] (long disorder prediction) to predict disorder propensity on all sequences and filtered out those that were significantly different from the disorder characteristics of the original ERD14 (different average disorder score or different disorder score variance); (iii) as the main reason for working with scrambled mutants was to test the effect of the amino acid composition only, we used the ANCHOR algorithm [34] to predict potential interaction regions and exclude sequences with high confidence interaction regions; (iv) as the randomized sequences turned out to be highly prone to generating regions with high coiled-coil propensity, we introduced a further filtering step: we used the COILS server [35] to predict coiled-coil regions and exclude sequences with high coiled-coil propensity; (v) as a final step, we used a charge distribution plot on the selected candidates (https://www.bioinformatics.nl/cgi-bin/emboss/charge (accessed on various dates in October 2016 and February 2017) to visually filter out sequences with uneven charge distribution. A more detailed description of the selection and post-filtering can be found in the Supplementary Methods.

\subsection{Expression and Purification of Recombinant Proteins}

The pET-22b (+) vector containing the appropriate construct was transformed into competent $E$. coli BL21 * (DE3) pLysS cells and grown in LB medium containing $0.05 \mathrm{mg} / \mathrm{mL}$ carbenicillin overnight at $37^{\circ} \mathrm{C}$ with shaking at $200 \mathrm{rpm}$. After inoculation with the starter cell culture into fresh $\mathrm{LB}$ medium containing $0.05 \mathrm{mg} / \mathrm{mL}$ carbenicillin, the cells were 
grown to $\mathrm{OD}_{600}=0.6-0.8$. Protein expression was induced with the addition $0.5 \mathrm{mM}$ IPTG, at $37^{\circ} \mathrm{C}$.

After $3 \mathrm{~h}$ of expression, cells were harvested by centrifugation at $4{ }^{\circ} \mathrm{C}$ at $4000 \mathrm{rpm}$ for $20 \mathrm{~min}$. The pellet was resuspended in lysis buffer ( $50 \mathrm{mM}$ Tris, $150 \mathrm{mM} \mathrm{NaCl}, 0.4 \mathrm{mM}$ DTE, pH 7.5) supplemented with a protease inhibitor tablet (Roche, Basel, Switzerland) prior to usage. Sonication was performed for $6 \times 15 \mathrm{~s}$ with $30 \mathrm{~s}$ pauses, on ice. Samples were centrifuged at $4{ }^{\circ} \mathrm{C} 5100 \mathrm{rpm}$ for $20 \mathrm{~min}$ to remove cell debris. Using the high temperature resistance of ERD14, boiling the supernatant was performed for 10-15 min to precipitate globular proteins. The denatured proteins were removed by centrifugation at $4{ }^{\circ} \mathrm{C}, 16,000 \mathrm{rpm}$ for $30 \mathrm{~min}$. The supernatant was filtered through a $0.2 \mu \mathrm{m}$ filter. The protein extract was purified with ÄKTAexplorer ${ }^{\mathrm{TM}}$ (GE Healthcare, Chicago, IL, USA) LC purification system. The first purification step was via buffer exchange on a HiPrep 26/10 Desalting column (GE Healthcare, Chicago, IL, USA). The sample was transferred to a $50 \mathrm{mM}$ Tris buffer ( $\mathrm{pH} 7.5)$.

Fractions containing ERD14 were purified on a Resource Q $6 \mathrm{~mL}$ (GE Healthcare, Chicago, IL, USA) anion exchange column. Elution was performed in $50 \mathrm{mM}$ Tris buffer ( $\mathrm{pH}$ 7.5) with a linear salt gradient up to $500 \mathrm{mM} \mathrm{NaCl}$. Fractions selected from the chromatogram were checked by SDS PAGE on a $15 \%$ gel. Based on the gel image, the fractions containing pure protein were dialyzed into $\mathrm{MQ}$ water. Dialysis was performed at $4{ }^{\circ} \mathrm{C} \mathrm{O} / \mathrm{N}$. The samples were lyophilized and stored at $-20{ }^{\circ} \mathrm{C}$ until usage.

\subsection{In Vitro Chaperone Assay}

Thermal denaturation of citrate synthase (CS) was monitored in the presence of WT, $\mathrm{FS}, \Delta \mathrm{Kc}$, and $\Delta \mathrm{S}$ ERD variants, using $\mathrm{CD}$ spectroscopy and an aggregation assay.

Thermal induced transitions were monitored in CD experiments by recording the ellipticity at $220 \mathrm{~nm}$, which is characteristic for the $\alpha$-helix structural component of citrate synthase. Changes in ellipticity induced by the increasing temperature were correlated with the thermal unfolding of the enzyme.

In the aggregation assay, citrate synthase was incubated at elevated temperature in itself or in the presence of different ERD14 constructs (WT, FS, $\Delta \mathrm{Kc}$, or $\Delta \mathrm{S}$ ) The amount of denatured CS was determined by measuring the protein concentration before and after heat stress, after removing the aggregated proteins by centrifugation. Detailed description of the methods can be found in the Supplementary Methods.

\subsection{Statistical Analysis}

To assess the statistical significance of the observed differences, a large number of intra- and inter-experiment replicates were done. The survival rates showed minimal standard deviation within the same experiment, and only slightly larger deviation between experiments with a Gaussian distribution. Unpaired t-tests were used to quantify the significance of the differences between survival rates of the differently transformed bacteria.

\subsection{Spectroscopy Measurements}

Circular dichroism (CD) spectroscopy experiments were carried out on a Jasco J-810 instrument (Japan Spectroscopic Co., Tokyo, Japan) equipped with a Peltier-controlled thermostat. For secondary structure determination in $10 \mathrm{mM} \mathrm{Na-phosphate,} \mathrm{pH} 7.4$ buffer, and in the presence of $30 \%$ trifluoro-ethanol (TFE), a quartz cell of $10 \mu \mathrm{M}$ pathlength was used with a protein concentration of $\sim 5 \mathrm{mg} / \mathrm{mL}$. Four scans were accumulated by using a scanning rate of $20 \mathrm{~nm} / \mathrm{min}$, a bandwidth of $1 \mathrm{~nm}$, and a data integration time of $4 \mathrm{~s}$.

SRCD spectra were recorded at the DISCO SRCD beamline of a SOLEIL Synchrotron (Gif-sur-Yvette, France). Experimental parameters were set by following the guidelines of Micsonai et al. [36]. Protein concentration was $\sim 5 \mathrm{mg} / \mathrm{mL}$ in $10 \mathrm{mM}$ Na-phosphate, pH 7.4, using a $12 \mu \mathrm{m} \mathrm{CaF}_{2}$ cell (Hellma GmbH, Müllcheim, Germany). At least 12 scans were accumulated in the $175-270 \mathrm{~nm}$ wavelength range at $1 \mathrm{~nm}$ steps with a lock-in time constant of $300 \mathrm{msec}$ and integration time of $1200 \mathrm{msec}$. The spectra were treated with the 
CDTool package [37] (averaging, baseline subtraction, correction with camphorsulphonic acid (CSA), normalization). Secondary structure composition was analyzed by the BeStSel algorithm [38].

For the $\mathrm{CD}$ measurements, the protein concentrations were determined directly in the $\mathrm{CD}$ cuvettes by the absorbances at 205 and $214 \mathrm{~nm}$. Measurements with the dialysis buffers were used as reference. The advantage of this method is that the extinction coefficients are large, even in the absence of aromatic residues, which is often the case for IDPs. Moreover, the actual CD samples are measured and thus any dilution errors or pathlength variations are taken into account. The extinction coefficients were calculated from the amino acid sequences on the BeStSel webserver (https:/ / bestsel.elte.hu (accessed on various dates in April, 2021) following the protocol of Antis and Clore [39] and Kuipers and Gruppen [40] for 205 and $214 \mathrm{~nm}$, respectively.

\subsection{Quantification of the Contribution of ERD14 Motifs to Cell Protection}

The protection of ERD14 and its various deletion and scrambled constructs of cells is primarily visualized through cell viability values measured after the applied stress (Supplementary Table S2). As viability before stress is taken as $100 \%$, we observe that the viability of control cells (cells with an empty vector, or cells expressing GST, calpastatin, or scrambled ERD14) drops to 38.2\% upon stress, whereas cells expressing ERD14 retain a viability of $74.5 \%$. To derive the contributions of individual motifs or their combinations to this protective activity, we developed a \% metric, which is $0 \%$ if addition of the motif keeps the activity of a given construct unchanged, whereas it is $100 \%$ if it raises its activity to the level of WT ERD14. As the background activity of a construct without the motif differs for the deletion and scrambling experiments, we have worked out a way to derive these two different values for the deletion and scrambled variants. For deletion constructs (e.g., $\Delta \mathrm{Kc}$ in WT background), we took the viability (V) of the deletion construct after stress and assumed that adding back the deleted segment(s) would increase viability back to $100 \%$ (as it reconstitutes WT ERD14), thus the contribution of the segment is:

For example, viability of cells expressing $\Delta \mathrm{K}_{\mathrm{c}}$ is 0.549 , which, upon "adding" $\mathrm{Kc}$ back, increases to 0.745 . That is, the Kc segment increases the activity by $0.745-0.549,53.99 \%$ of the potential maximum (cf. Table S2 and Figure 5C).

For scrambled mutants (e.g., Scr-Kc), we assumed that activity without the motif at $38.2 \%$ chaperone activity is $\%$ (because Full-Scr ERD14 exerts no protection), thus the measured actual $\mathrm{V}$ value represents the activity associated with the motif:

For example, viability of Scr-Kc is 0.397 , i.e., Kc alone can add to the activity of Full-Scr ERD14 0.397-0.382, about $4.13 \%$ of the possible maximum (cf. Supplementary Table S2 and Figure 5C).

Supplementary Materials: The following are available online at https://www.mdpi.com/article/10 .3390/ijms22126190/s1, Supplementary methods References [41-51]; Figure S1: Expression levels of ERD14 constructs in E. coli cells; Figure S2: Dose-effect correlation of ERD14; Figure S3: In vitro chaperone effect of different ERD14 constructs; Table S1: Sequences of ERD14 constructs and controls; Table S2: E. coli viability measurements; Table S3: Remaining residues in helix by deletion of different segments and the effects for the survival rates; Table S4: Melting temperature change of Citrate synthase in the presence of different ERD14 protein constructs.

Author Contributions: Conceptualization, P.T., L.B. and K.-H.H.; methodology, P.T., L.K., J.K. and A.T.; validation, P.T. and J.K.; formal analysis, N.M., A.M. and J.K.; investigation, N.M., A.M., J.K. and B.S.; resources, A.T.; data curation, N.M. and J.K.; software: L.K. and E.S., writing-original draft preparation, P.T. and A.T.; writing-review and editing, N.M., J.K., E.S. and A.T.; visualization, N.M. and J.K.; supervision, P.T. and A.T.; project administration, A.T.; funding acquisition, P.T., J.K., A.M., L.B, K.-H.H. and A.T. All authors have read and agreed to the published version of the manuscript.

Funding: This work was supported by the FWO Odysseus grant G.0029.12 (P.T.) from Research Foundation Flanders (FWO), the Korea-Hungarian Joint Laboratory program 2010-88343 (K.-H.H., P.T.) from the Korea Research Council of Fundamental Science and Technology (KRCF), the National 
Research Council of Science and Technology (NST) grant NTM2231712 (K.-H.H., P.T.), grants K124670 and K131702 (P.T.), K125340 (A.T.), K120391 and KH125597, (J.K., A.M.) and PD135510 (A.M.) from the National Research, Development and Innovation Office, Hungary, a János Bolyai research scholarship (A.M., L.K.), SOLEIL Synchrotron, France (proposals 20171582, 20180805, 20181890) and a Lendület grant (L.B.) from the Hungarian Academy of Sciences. The APC was funded by the National Research, Development and Innovation Office, Hungary (grant K131702).

Institutional Review Board Statement: Not applicable.

Informed Consent Statement: Not applicable.

Data Availability Statement: The data presented in this study are available in the Supplementary Materials section.

Conflicts of Interest: The authors declare no conflict of interest.

\section{References}

1. Ul Haq, S.; Khan, A.; Ali, M.; Khattak, A.M.; Gai, W.-X.; Zhang, H.-X.; Wei, A.-M.; Gong, Z.-H. Heat Shock Proteins: Dynamic Biomolecules to Counter Plant Biotic and Abiotic Stresses. Int. J. Mol. Sci. 2019, 20, 5321. [CrossRef]

2. Suss, O.; Reichmann, D. Protein plasticity underlines activation and function of ATP-independent chaperones. Front. Mol. Biosci. 2015, 2, 43. [CrossRef] [PubMed]

3. Kovacs, D.; Szabo, B.; Pancsa, R.; Tompa, P. Intrinsically disordered proteins undergo and assist folding transitions in the proteome. Arch. Biochem. Biophys. 2013, 531, 80-89. [CrossRef] [PubMed]

4. Hanin, M.; Brini, F.; Ebel, C.; Toda, Y.; Takeda, S.; Masmoudi, K. Plant dehydrins and stress tolerance: Versatile proteins for complex mechanisms. Plant Signal. Behav. 2011, 6, 1503-1509. [CrossRef] [PubMed]

5. Storey, J.M.; Storey, K.B. Sensing, Signaling and Cell Adaptation; Elsevier: Amsterdam, The Netherlands, 2002.

6. Close, T.J. Dehydrins: Emergence of a biochemical role of a family of plant dehydration proteins. Physiol. Plant. 1996, 97, 795-803. [CrossRef]

7. Cuevas-Velazquez, C.L.; Saab-Rincón, G.; Reyes, J.L.; Covarrubias, A.A. The Unstructured N-terminal Region of Arabidopsis Group 4 Late Embryogenesis Abundant (LEA) Proteins Is Required for Folding and for Chaperone-like Activity under Water Deficit. J. Biol. Chem. 2016, 291, 10893-10903. [CrossRef]

8. Lv, A.; Su, L.; Liu, X.; Xing, Q.; Huang, B.; An, Y.; Zhou, P. Characterization of Dehydrin protein, CdDHN4-L and CdDHN4-S, and their differential protective roles against abiotic stress in vitro. BMC Plant Biol. 2018, 18, 299. [CrossRef]

9. Murvai, N.; Kalmar, L.; Szalaine Agoston, B.; Szabo, B.; Tantos, A.; Csikos, G.; Micsonai, A.; Kardos, J.; Vertommen, D.; Nguyen, P.N. Interplay of Structural Disorder and Short Binding Elements in the Cellular Chaperone Function of Plant Dehydrin ERD14. Cells 2020, 9, 1856. [CrossRef]

10. Lüttge, U.; Beck, E.; Bartels, D. Plant Desiccation Tolerance; Springer Science \& Business Media: Berlin/Heidelberg, Germany, 2011.

11. Artur, M.A.S.; Zhao, T.; Ligterink, W.; Schranz, E.; Hilhorst, H.W.M. Dissecting the Genomic Diversification of Late Embryogenesis Abundant (LEA) Protein Gene Families in Plants. Genome Biol. Evol. 2019, 11, 459-471. [CrossRef]

12. Hundertmark, M.; Hincha, D.K. LEA (late embryogenesis abundant) proteins and their encoding genes in Arabidopsis thaliana. BMC Genom. 2008, 9, 118. [CrossRef]

13. Priya, M.; Dhanker, O.P.; Siddique, K.H.M.; Hanumantha Rao, B.; Nair, R.M.; Pandey, S.; Singh, S.; Varshney, V.K.; Vara Prasad, P.V.; Nayyar, H. Drought and heat stress-related proteins: An update about their functional relevance in imparting stress tolerance in agricultural crops. Theor. Appl. Genet. 2019, 132, 1607-1638. [CrossRef]

14. Kovacs, D.; Kalmar, E.; Torok, Z.; Tompa, P. Chaperone activity of ERD10 and ERD14, two disordered stress-related plant proteins. Plant Physiol. 2008, 147, 381-390. [CrossRef]

15. Nguyen, P.N.; Tossounian, M.-A.; Kovacs, D.S.; Thu, T.T.; Stijlemans, B.; Vertommen, D.; Pauwels, J.; Gevaert, K.; Angenon, K.; Messens, J. Dehydrin ERD14 activates glutathione transferase Phi9 in Arabidopsis thaliana under osmotic stress. Biochim. Biophys. Acta Gen. Subj. 2020, 1864, 129506. [CrossRef]

16. Szalainé Ágoston, B.; Kovács, D.; Tompa, P.; Perczel, A. Full backbone assignment and dynamics of the intrinsically disordered dehydrin ERD14. Biomol. NMR Assign. 2011, 5, 189-193. [CrossRef] [PubMed]

17. Camilloni, C.; De Simone, A.; Vranken, W.F.; Vendruscolo, M. Determination of secondary structure populations in disordered states of proteins using nuclear magnetic resonance chemical shifts. Biochemistry 2012, 51, 2224-2231. [CrossRef] [PubMed]

18. Rost, B.; Sander, C. Prediction of protein secondary structure at better than 70\% accuracy. J. Mol. Biol. 1993, 232, 584-599. [CrossRef] [PubMed]

19. Elnaggar, A.; Heinzinger, M.; Dallago, C.; Rehawi, G.; Wang, Y.; Jones, L.; Gibbs, T.; Feher, T.; Angerer, C.; Steinegger, M. ProtTrans: Towards Cracking the Language of Life's Code Through Self-Supervised Deep Learning and High Performance Computing. bioRxiv 2020. [CrossRef]

20. Yachdav, G.; Kloppmann, E.; Kajan, L.; Hecht, M.; Goldberg, T.; Hamp, T.; Hönigschmid, P.; Schafferhans, A.; Roos, M.; Bernhofer, M. PredictProtein-An open resource for online prediction of protein structural and functional features. Nucleic Acids Res. 2014, 42, W337-W343. [CrossRef] 
21. Chakrabortee, S.; Boschetti, C.; Walton, L.J.; Sarkar, S.; Rubinsztein, D.C.; Tunnacliffe, A. Hydrophilic protein associated with desiccation tolerance exhibits broad protein stabilization function. Proc. Natl. Acad. Sci. USA 2007, 104, 18073-18078. [CrossRef]

22. Wu, Y.; Liu, C.; Kuang, J.; Ge, Q.; Zhang, Y.; Wang, Z. Overexpression of SmLEA enhances salt and drought tolerance in Escherichia coli and Salvia miltiorrhiza. Protoplasma 2014, 251, 1191-1199. [CrossRef]

23. Ling, H.; Zeng, X.; Guo, S. Functional insights into the late embryogenesis abundant (LEA) protein family from Dendrobium officinale (Orchidaceae) using an Escherichia coli system. Sci. Rep. 2016, 6, 39693. [CrossRef] [PubMed]

24. Graether, S.P.; Boddington, K.F. Disorder and function: A review of the dehydrin protein family. Front. Plant Sci. 2014, 5, 576. [CrossRef] [PubMed]

25. Covarrubias, A.A.; Cuevas-Velazquez, C.L.; Romero-Pérez, P.S.; Rendón-Luna, D.F.; Chater, C.C.C. Structural disorder in plant proteins: Where plasticity meets sessility. Cell. Mol. Life Sci. 2017, 74, 3119-3147. [CrossRef] [PubMed]

26. Haynes, C.; Iakoucheva, L.M. Serine/arginine-rich splicing factors belong to a class of intrinsically disordered proteins. Nucleic Acids Res. 2006, 34, 305-312. [CrossRef]

27. Pery, R.N.; Wharton, D.A. Molecular and Physiological Basis of Nematode Survival; CABI: Oxfordshire, UK, 2011.

28. Ingram, J.; Bartels, D. The Molecular Basis of Dehydratation Tolerance in Plants. Annu. Rev. Plant Physiol. Plant Mol. Biol. 1996, 47, 377-403. [CrossRef]

29. McClellan, A.J.; Xia, Y.; Deutschbauer, A.M.; Davis, R.W.; Gerstein, M.; Frydman, J. Diverse cellular functions of the Hsp90 molecular chaperone uncovered using systems approaches. Cell 2007, 131, 121-135. [CrossRef] [PubMed]

30. Rorat, T. Plant dehydrins-Tissue location, structure and function. Cell. Mol. Biol. Lett. 2006, 11, 536-556. [CrossRef]

31. Maszkowska, J.; Dębski, J.; Kulik, A.; Kistowski, M.; Bucholc, M.; Lichocka, M.; Klimecka, M.; Sztatelman, O.; Patrycja Szymańska, K.; Dadlez, M. Phosphoproteomic analysis reveals that dehydrins ERD10 and ERD14 are phosphorylated by SNF1-related protein kinase 2.10 in response to osmotic stress. Plant Cell Environ. 2019, 42, 931-946. [CrossRef]

32. Brini, F.; Hanin, M.; Lumbreras, V.; Irar, S.; Pagès, M.; Masmoudi, K. Functional characterization of DHN-5, a dehydrin showing a differential phosphorylation pattern in two Tunisian durum wheat (Triticum durum Desf.) varieties with marked differences in salt and drought tolerance. Plant Sci. 2007, 172, 20-28. [CrossRef]

33. Dosztanyi, Z.; Csizmok, V.; Tompa, P.; Simon, I. IUPred: Web server for the prediction of intrinsically unstructured regions of proteins based on estimated energy content. Bioinformatics 2005, 3433-3434. [CrossRef]

34. Mészáros, B.; Simon, I.; Dosztányi, Z. Prediction of Protein Binding Regions in Disordered Proteins. PLoS Comput. Biol. 2009, e1000376. [CrossRef] [PubMed]

35. Lupas, A.; Van Dyke, M.; Stock, J. Predicting coiled coils from protein sequences. Science 1991, 252, 1162-1164. [CrossRef]

36. Micsonai, A.; Bulyáki, É.; Kardos, J. BeStSel: From Secondary Structure Analysis to Protein Fold Prediction by Circular Dichroism Spectroscopy. Methods Mol. Biol. 2021, 2199, 175-189.

37. Lees, J.G.; Smith, B.R.; Wien, F.; Miles, A.J.; Wallace, B.A. CDtool-an integrated software package for circular dichroism spectroscopic data processing, analysis, and archiving. Anal. Biochem. 2004, 332, 285-289. [CrossRef]

38. Micsonai, A.; Wien, F.; Bulyáki, É.; Kun, J.; Moussong, É.; Lee, Y.-H.; Goto, Y.; Réfrégiers, M.; Kardos, J. BeStSel: A web server for accurate protein secondary structure prediction and fold recognition from the circular dichroism spectra. Nucleic Acids Res. 2018, 46, W315-W322. [CrossRef]

39. Anthis, N.J.; Marius Clore, G. Sequence-specific determination of protein and peptide concentrations by absorbance at $205 \mathrm{~nm}$. Protein Sci. 2013, 851-858. [CrossRef]

40. Kuipers, B.J.H.; Gruppen, H. Prediction of molar extinction coefficients of proteins and peptides using UV absorption of the constituent amino acids at $214 \mathrm{~nm}$ to enable quantitative reverse phase high-performance liquid chromatography-mass spectrometry analysis. J. Agric. Food Chem. 2007, 55, 5445-5451. [CrossRef] [PubMed]

41. Kumar, M.; Gouw, M.; Michael, S.; Sámano-Sánchez, H.; Pancsa, R.; Glavina, J.; Diakogianni, A.; Valverde, J.A.; Bukirova, D.; Čalyševa, J. ELM-the eukaryotic linear motif resource in 2020. Nucleic Acids Res. 2020, 48, D296-D306. [CrossRef] [PubMed]

42. Mistry, J.; Chuguransky, S.; Williams, L.; Qureshi, M.; Salazar, G.A.; Sonnhammer, E.L.L.; Tosatto, S.C.E.; Paladin, L.; Raj, S.; Richardson, L.J. Pfam: The protein families database in 2021. Nucleic Acids Res. 2021, 49, D412-D419. [CrossRef] [PubMed]

43. Walsh, I.; Seno, F.; Tosatto, S.C.E.; Trovato, A. PASTA 2.0: An improved server for protein aggregation prediction. Nucleic Acids Res. 2014, 42, W301-W307. [CrossRef] [PubMed]

44. Conchillo-Solé, O.; de Groot, N.S.; Avilés, F.X.; Vendrell, J.; Daura, X.; Ventura, S. AGGRESCAN: A server for the prediction and evaluation of "hot spots" of aggregation in polypeptides. BMC Bioinform. 2007, 8, 65. [CrossRef]

45. Muñoz, V.; Serrano, L. Elucidating the folding problem of helical peptides using empirical parameters. Nat. Struct. Biol. 1994, 1, 399-409. [CrossRef] [PubMed]

46. Muñoz, V.; Serrano, L. Elucidating the folding problem of helical peptides using empirical parameters. II. Helix macrodipole effects and rational modification of the helical content of natural peptides. J. Mol. Biol. 1995, 245, 275-296. [CrossRef]

47. Muñoz, V.; Serrano, L. Elucidating the folding problem of helical peptides using empirical parameters. III. Temperature and pH dependence. J. Mol. Biol. 1995, 245, 297-308. [CrossRef]

48. Muñoz, V.; Serrano, L. Development of the multiple sequence approximation within the AGADIR model of $\alpha$-helix formation: Comparison with Zimm-Bragg and Lifson-Roig formalisms. Biopolymers 1997, 495-509. [CrossRef] 
49. Lacroix, E.; Viguera, A.R.; Serrano, L. Elucidating the folding problem of $\alpha$-helices: Local motifs, long-range electrostatics, ionic-strength dependence and prediction of NMR parameters 1 1Edited by A. R. Fersht. J. Mol. Biol. 1998, 173-191. [CrossRef] [PubMed]

50. Bernhofer, M.; Dallago, C.; Karl, T.; Satagopam, V.; Heinzinger, M.; Littmann, M.; Olenyi, T.; Qiu, J.; Schütze, K.; Yachdav, G. PredictProtein-Predicting Protein Structure and Function for 29 Years. Nucleic Acids Res. 2021. [CrossRef]

51. Shih, P.; Holland, D.R.; Kirsch, J.F. Thermal stability determinants of chicken egg-white lysozyme core mutants: Hydrophobicity, packing volume, and conserved buried water molecules. Protein Sci. 1995, 4, 2050-2062. [CrossRef] [PubMed] 